\title{
Predicting weight status in Chinese pre-school children: independent and interactive effects of caregiver types and feeding styles
}

\author{
Xiaotong Wei ${ }^{1}$, Yanan $\mathrm{Ma}^{2}$, Jiajin $\mathrm{Hu}^{2}$, Wenjing Lin ${ }^{1}$, Zhongyi Zhao ${ }^{2}$ and Deliang Wen ${ }^{2, *}$ \\ 'Public Health Department, Dalian Medical University, Dalian, Liaoning Province, People's Republic of China: \\ ${ }^{2}$ China Medical University, No. 77 Puhe Road, Shenyang North New Area, Shenyang 1 10001, Liaoning Province, \\ People's Republic of China
}

Submitted 12 July 2017: Final revision received 16 October 2017: Accepted 23 October 2017: First published online 6 December 2017

\begin{abstract}
Objective: To investigate caregiver type as a potential moderating effect in the relationship between feeding style and weight status among Chinese pre-school children.

Design: Cross-sectional data collected with the Caregiver's Feeding Style Questionnaire (CFSQ), anthropometric data, childcare and sociodemographic information. Setting: Shenyang, China.

Subjects: Caregiver-child dyads ( $n$ 857).

Results: After controlling for confounders, authoritarian feeding style was associated with a 0.30 lower BMI $Z$-score. Fathers as primary caregivers were related to lower BMI $Z$-score $(\beta=-0 \cdot 66)$, while grandparents as main caregivers were associated with higher BMI $Z$-score $(\beta=0.66)$ after adjusting for covariates. Mothers buffered the relationship between authoritarian $(\beta=0.50,95 \%$ CI 0.04 , $0.95)$ or indulgent $(\beta=-0.60,95 \% \mathrm{CI}-1 \cdot 06,-0 \cdot 14)$ feeding styles and BMI $Z$-score. Grandparents strengthened the trend that indulgent feeding style was related to higher BMI $Z$-score $(\beta=0.54,95 \%$ CI $0 \cdot 01,1 \cdot 08)$.

Conclusions: The results of independent and interactive effects of specific feeding styles and caregiver types had different influences on child BMI $Z$-scores. Longitudinal investigations are needed to evaluate the effect of fathers' and grandparents' feeding on their children's nutrition and weight status.
\end{abstract}

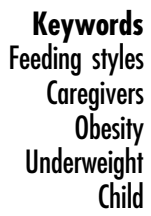

Childhood weight problems have become a crucial challenge to global health. Global overweight and obesity rates among children increased by $47 \cdot 1 \%$ from 1980 to $2013^{(1)}$. Underweight also exert effects on childhood well-being $^{(2)}$. In developed countries, 3-8\% of children are underweight, while the rate is about $16 \%$ in developing countries ${ }^{(3)}$. Studies show that weight problems tend to have an adverse impact on health and predict a wide range of mortality and future morbidity, especially for children under 5 years of age ${ }^{(1,2)}$. Overweight and obese children are at higher risk of diabetes, CVD and psychosocial problems that extend into adulthood ${ }^{(4)}$. Moreover, underweight in early childhood is related to future $\mathrm{CHD}^{(5)}$. While weight status in toddlers and schoolaged children has been extensively studied, the crucial transitional pre-school age of 3-5 years still garners further research ${ }^{(6,7)}$. Pre-school children are not only in the period of the adiposity rebound, but also fill the age gap between toddlers and school-aged children ${ }^{(8)}$.

Given the growth trend of childhood weight problems, it is crucial to explore the contributing factors. Caregivers not only establish the eating environment but also have an impact on children's dietary patterns via eating beliefs, attitudes and practices, especially in pre-school children ${ }^{(9)}$. Feeding styles could influence how caregivers modify or maintain children's diets based on their techniques or behaviours, which in turn affects a child's weight status ${ }^{(10)}$. Hughes et al. categorized caregivers' feeding style into four categories: authoritative style (caregivers allow children take appropriate foods with reasoning and make clear expectations and guidelines that children are aware of); authoritarian style (caregivers punish children to follow strict food rules and do not make any adjustments or exceptions based on the child's perspectives); indulgent style (caregivers are accepting and warm but rarely make requirements with regard to food); and uninvolved style (caregivers make few demands on children to eat but are unsupportive) ${ }^{(11)}$. Across a series of previous studies, indulgent feeding styles were related to higher BMI $Z$-scores or weight status ${ }^{(11-14)}$, while the relationships of authoritative, authoritarian and uninvolved feeding styles with children's BMI were inconsistent ${ }^{(15-19)}$.

Extant research has chiefly concentrated on maternal feeding and weight problems, but there is a distinct lack 
of research evaluating the role of grandparents and fathers as the main moderator of the relationship between children's feeding and BMI ${ }^{(20,21)}$. With changes in society and the redefinition of the patriarchal relationship, fathers are becoming more involved in child feeding time ${ }^{(22)}$. The National Center for Health Statistics showed that $72 \%$ of US fathers were involved on a daily basis in feeding children under 5 years old ${ }^{(23)}$. However, the connection between paternal influences and offspring weight status is still inconclusive ${ }^{(24)}$. For instance, children who were regularly taken care of by their fathers were 1.9 times as likely to be overweight or obese in Korea ${ }^{(25)}$. On the contrary, Chinese children who were mainly cared for by their fathers had a $32 \%$ increase of underweight compared with children cared for by their mothers ${ }^{(26)}$. The conflicting result may be driven by feeding styles. One study concluded that the father's feeding style is not associated with a child's weight status ${ }^{(24)}$. However, other studies showed that mothers and fathers have different feeding influences on their children's weight status ${ }^{(27)}$. A review paper suggested that fathers' feeding, independent of maternal factors, may affect children's BMI ${ }^{(28)}$.

Currently, grandparents also play an important role in feeding, particularly when mothers, as the traditional caregiver, encounter pressure from both housework and employment ${ }^{(29)}$. Twenty-seven per cent of grandparents in American families and $24 \%$ in British families are the primary caregivers of children ${ }^{(30)}$. Forty-three per cent of Hispanic parents reported that there was at least one grandparent involved in their children's caregiving ${ }^{(31)}$. In Japan, $52.3 \%$ of families rely on grandparents to care for the child until at least 3 years old ${ }^{(32)}$. Due to the importance of ethnicity and spread of culture, the situation in China should be especially taken into consideration. In 2015, the Chinese government introduced the two-child policy ${ }^{(33)}$, which meant more urban grandparents would be shouldering the responsibility of taking care of the second grandchild ${ }^{(8)}$. According to the China Health and Nutrition Survey, more than half of grandparents help parents rear their offspring ${ }^{(29)}$.

Past studies have shown that grandparent care is closely related with child weight status ${ }^{(32,34,35)}$. Contrary to parental and formal childcare, childcare by grandparents has been related to higher BMI in pre-school children, as concluded by research from the $\mathrm{UK}^{(34)}$ and the USA ${ }^{(35)}$. The Japanese Ibaraki Children's Cohort Study stated that being cared for by grandparents at age 3 years was associated with increased mean BMI from childhood to adulthood $^{(32)}$. In China, children who were cared for primarily by their grandparents were more than twice as likely to be overweight and obese ${ }^{(21)}$. These findings partially support that grandparents' indulgent feeding style was more likely to increase the risk of overweight or obesity in children ${ }^{(20)}$. However, current available research boasts very few quantitative studies to discuss this topic ${ }^{(21,30)}$.
The present study investigated the associations among caregivers' type, feeding styles and BMI of Chinese pre-school children. Specifically, the independent and interaction of three caregiver types (mother, father and grandparent) and four feeding styles (authoritative, authoritarian, indulgent and uninvolved) in predicting children's BMI Z-scores were explored. According to previous literature, we hypothesized that feeding style and the type of caregiver would be independently related to child BMI $Z$-scores. Second, the effects of feeding styles and caregiver types on child BMI may be additive or offset. For example, a child may have a higher BMI Z-score if $s /$ he is taken care of by a grandparent using the indulgent feeding style.

\section{Methods}

\section{Procedures and participants}

A cross-sectional survey was conducted in Shenyang, an urban city in northern China. Stratified-cluster sampling was carried out according to districts and kindergartens. Four districts were randomly selected based on the 2015 Liaoning Economic Statistical Yearbook ${ }^{(36)}$. The number of kindergartens was estimated based on registered directories at district education offices. After approval for participation was obtained from the principal of a kindergarten, teachers of the kindergarten requested pre-school children to bring the consent forms and questionnaires home to their caregivers. Participants sent the completed questionnaires back to teachers the next school day. Written informed consent was acquired from all caregivers.

Between June and August 2015, 1010 caregivers' questionnaires were distributed. Caregiver-child dyads were acceptable if the following criteria were met: (i) the respondent must play the primary role in taking care of the child and must have knowledge of the child's dietary habits and patterns; (ii) the family was of Chinese ethnicity; (iii) if the participating family had more than one child enrolled in the kindergarten, the primary caregiver should fill out the questionnaire based on information regarding the eldest child; and (iv) the child was aged 3-5 years and did not have any chronic metabolic diseases or birth defects.

\section{Demographic characteristics}

Data were collected via questionnaires on various basic demographic characteristics of the caregiver and their child aged 3-5 years. Demographic information included the child's sex, age, birth weight, and whether s/he was the only child in the family. In addition, caregivers reported their education level (elementary school or below, secondary school, diploma/degree or higher) and household monthly income. 


\section{Anthropometric data}

After teachers explained the importance of the accuracy of measurements, children's weights and heights were measured at home. After removing their shoes and bulky clothing, children were measured in their street clothes. BMI was calculated by caregiver respondents, who provided information for each dyad $\left(\mathrm{kg} / \mathrm{m}^{2}\right)$. The preschool child's BMI was transformed into a $Z$-score corresponding to the age- and sex-specific reference outlined by the $\mathrm{WHO}^{(37)}$. International cut-offs were used to classify children into four weight groups: underweight ${ }^{(38)}$, normal weight, overweight and obesity ${ }^{(39)}$.

\section{Childcare}

Information obtained from the item, 'As your child's primary caregiver, what is your relationship to the child?', was used to determine the identity of the "primary caregiver'. Caregiver types included: (i) mothers; (ii) grandparents; and (iii) fathers.

\section{Caregiver's Feeding Style Questionnaire}

The Caregiver's Feeding Style Questionnaire (CFSQ) was originally used to collect data on feeding styles in lowincome families with pre-school children ${ }^{(11)}$. Using a Chinese version with translation-back-translation ${ }^{(40)}$, reliability was pre-tested with a sample of 102 participants from kindergartens in Shenyang. The Chinese version of the CFSQ was a twenty-five-item questionnaire utilizing Likert-scaled responses ( $1=$ 'never' to $5=$ 'always'). To categorize caregivers' feeding styles, the critical value of the demandingness subscale was split at the median score and the critical value of the responsiveness subscale was the ratio of the median of the child-centred factor to the median of demandingness. According to dichotomous standards, caregivers' feeding styles were divided into authoritative (high demandingness, high responsiveness), authoritarian (high demandingness, low responsiveness), indulgent (low demandingness, high responsiveness) and uninvolved (low demandingness, low responsiveness).

\section{Statistical analyses}

All data analyses were run using the statistical software package IBM SPSS Statistics version 20.0 (2011). Descriptive statistics explored dispersion, percentile and centralized tendency according to caregiver type. Bivariate associations among predictors, covariates and outcomes were carried out. Spearman's correlation coefficients were reported for dichotomous variables, while Pearson's correlation coefficients were analysed for continuous variables.

Linear regression models were used to examine the relationships between feeding styles and child BMI $Z$-scores and between caregiver types and child BMI $Z$-scores. Based on the literature ${ }^{(12,14,32)}$, authoritative feeding style and mother were set as references for feeding style and caregiver type, respectively, and were adjusted by child's sex, age, birth weight, whether or not the child was an only child, and caregiver's education status and family income. Interaction analysis was conducted by Hayes' PROCESS macro (Model 1) ${ }^{(41)}$. After centralizing variables, predictors were one of the feeding styles (authoritative, authoritarian, indulgent or uninvolved) and moderating variables were one of the caregiver types (mother, grandparent or father). Covariates were the same as mentioned before. Interactions were interpreted and graphed by the methods of Aiken and West ${ }^{(42)}$.

\section{Results}

Completed questionnaires were collected from 857 of 1010 caregivers (response rate: 84.9\%). The number of missing data across all items was low, so mean substitution was used to evaluate missing values. No outliers were detected in the database.

Demographic information is summarized in Table 1. Mean age of the children was 3.8 (SD 0.8) years. Sex assumed an even distribution among children (51.5\% male). The majority of caregivers were mothers (68.7\%), while $148(17 \cdot 3 \%)$ children had their father as the primary caregiver and 120 (14.0\%) were cared for primarily by grandparents. These patterns varied by caregivers' education $(P<0.001)$ but not weight status.

Table 2 displays the correlation matrix for all key variables. Indulgent feeding style was positively related to child BMI Z-score. Mothers were inversely linked to indulgent feeding style, but grandparents were positively associated with indulgent feeding style. Grandparents were negatively related to authoritarian feeding style. Finally, there was a positive correlation between grandparents and child BMI $Z$-score.

After controlling for confounders, authoritarian feeding style was associated with a 0.30 lower BMI $Z$-score. After adjusting for covariates, fathers as primary caregivers were related to lower BMI $Z$-scores $(\beta=-0 \cdot 66)$, while grandparents as main caregiver were associated with higher BMI $Z$-scores $(\beta=0 \cdot 66$; Table 3$)$.

Moderation effects categorized by caregiver type and controlled for confounders are shown in Table 4. The relationship between authoritarian feeding and child BMI was significant for mothers $(\beta=0.50,95 \%$ CI $0.04,0.95)$. The interaction effect accounted for $5.4 \%$ of additional variance in child BMI $Z$-score. Moreover, the association between indulgent feeding style and BMI $Z$-score differed as a function of mothers $(\beta=-0 \cdot 60,95 \% \mathrm{CI}-1 \cdot 06,-0 \cdot 14)$. There was a growth in $R^{2}\left(\Delta R^{2}=0.078\right)$ after adding the interaction.

Indulgent feeding style did, however, significantly affect child BMI $Z$-score when grandparents were added into the model as a moderator $(\beta=0.54$, $95 \%$ CI $0.01,1.08)$. A marginally significant indulgent 
Table 1 Demographic information of children and caregivers ( $n$ 857) from Shenyang, northern China, June-August 2015

\begin{tabular}{|c|c|c|c|c|c|c|}
\hline & \multicolumn{2}{|c|}{$\begin{array}{l}\text { Fathers } \\
(n 148)\end{array}$} & \multicolumn{2}{|c|}{$\begin{array}{l}\text { Mothers } \\
\text { (n 589) }\end{array}$} & \multicolumn{2}{|c|}{$\begin{array}{l}\text { Grandparents } \\
\quad(n 120)\end{array}$} \\
\hline & Mean or $n$ & SD or $\%$ & Mean or $n$ & SD or $\%$ & Mean or $n$ & SD or $\%$ \\
\hline \multicolumn{7}{|l|}{ Child } \\
\hline Age (years), mean and SD & $3 \cdot 8$ & 0.78 & 3.8 & 0.78 & $3 \cdot 8$ & 0.77 \\
\hline Male, $n$ and $\%$ & 86 & $58 \cdot 1$ & 292 & 49.6 & 63 & 52.5 \\
\hline Only child, $n$ and \% & 128 & 86.5 & 502 & $85 \cdot 7$ & 100 & 84.0 \\
\hline Birth weight $(\mathrm{kg})$, mean and $\mathrm{SD}$ & 3.39 & 0.54 & 3.45 & 0.51 & 3.41 & 0.58 \\
\hline BMI Z-score, mean and SD & 0.14 & 1.64 & 0.34 & 1.56 & 0.21 & 1.55 \\
\hline \multicolumn{7}{|l|}{ BMl category, $n$ and $\%$} \\
\hline Underweight & 35 & 23.6 & 111 & $18 \cdot 8$ & 28 & 23.3 \\
\hline Normal & 67 & $45 \cdot 3$ & 303 & 51.4 & 54 & $45 \cdot 0$ \\
\hline Overweight & 23 & $15 \cdot 5$ & 74 & $12 \cdot 6$ & 20 & $16 \cdot 7$ \\
\hline Obesity & 23 & $15 \cdot 5$ & 101 & $17 \cdot 1$ & 18 & $15 \cdot 0$ \\
\hline \multicolumn{7}{|l|}{ Caregiver } \\
\hline \multicolumn{7}{|l|}{ Educational status, $n$ and $\%$} \\
\hline Primary school or below & 10 & $6 \cdot 8$ & 32 & 5.4 & 45 & $37 \cdot 8$ \\
\hline Secondary school & 61 & 41.2 & 269 & $45 \cdot 7$ & 60 & $50 \cdot 4$ \\
\hline Diploma/degree or higher & 77 & $52 \cdot 0$ & 288 & 48.9 & 15 & $11 \cdot 8$ \\
\hline \multicolumn{7}{|c|}{ Household income per month (Yuan) } \\
\hline Median & \multicolumn{2}{|c|}{8000} & \multicolumn{2}{|c|}{8000} & \multicolumn{2}{|c|}{6000} \\
\hline IQR & \multicolumn{2}{|c|}{6000} & \multicolumn{2}{|c|}{5000} & \multicolumn{2}{|c|}{5000} \\
\hline \multicolumn{7}{|l|}{ Feeding style, $n$ and $\%$} \\
\hline Authoritative & 24 & $16 \cdot 2$ & 78 & $13 \cdot 2$ & 15 & $12 \cdot 5$ \\
\hline Authoritarian & 63 & $42 \cdot \overline{6}$ & 237 & $40 . \overline{2}$ & 40 & 33.5 \\
\hline Indulgent & 44 & 29.7 & 203 & 34.5 & 45 & $37 \cdot 3$ \\
\hline Uninvolved & 17 & 11.5 & 71 & $12 \cdot 1$ & 20 & $16 \cdot 7$ \\
\hline
\end{tabular}

IQR, interquartile range.

feeding style $\times$ grandparent interaction $\left(\Delta R^{2}=0 \cdot 046\right)$ could be observed. The above models adjusted for relevant covariates. Thus, our second hypothesis was partially supported by these results.

\section{Discussion}

The present study examined the independent and interactive effects of specific feeding styles and caregiver types in predicting child BMI $Z$-scores. Mothers buffered two relationships: (i) authoritarian feeding style was inversely associated with BMI $Z$-score; and (ii) indulgent feeding style was positively related to BMI $Z$-score. Grandparents strengthened the association between indulgent feeding style and BMI $Z$-score. Nevertheless, fathers were independently associated with lower child BMI $Z$-score, but did not have any other moderating effect.

\section{Fathers v. mothers}

The authoritarian feeding style was independently related to lower child BMI $Z$-score, which agrees with a previous study $^{(17)}$. However, several prior studies showed either inconclusive or conflicting results for this feeding style ${ }^{(15)}$. The cause of the discrepancy could be attributed to the primary caregiver. Two studies of varying parent-child dyads found that authoritarian feeding style was more likely to produce underweight status than other styles $^{(11,12)}$. In contrast, a study of only mother-child dyads determined that authoritarian feeding style was not connected with child weight status ${ }^{(13)}$. The present study showed similar results, where mothers decreased the negative effect of authoritarian feeding on BMI $Z$-score. In addition, according to linear regression analysis, fathers reported as the main caregiver was independently associated with an increased risk for children being underweight. Although fathers may prevent children from overweight or obesity, there is a call for further research in this regard and on its benefits before fathers can be promoted as primary caregivers.

Based on literature comparing feeding differences between mothers and fathers, fathers were shown to rarely make efforts to praise the child and often utilized neutral prompts or reasoning ${ }^{(43)}$, making fathers seem more disconnected and aloof. Results from other research indicated that maternal feeding activities reported a higher level of responsibility than paternal ${ }^{(40)}$. Therefore, children who were regularly fed by authoritarian mothers may have been more likely to be normal weight. On the contrary, results from the present study showed that all feeding styles used by fathers as main caregivers would account for a lower weight in the child.

\section{Grandparents v. mothers}

The present results differed from recent studies on indulgent feeding style ${ }^{(13,14)}$, where there was a link to higher BMI Z-score only with grandparent primary caregivers' interaction in the model. A converse pattern demonstrated that mothers attenuated the association between indulgent 


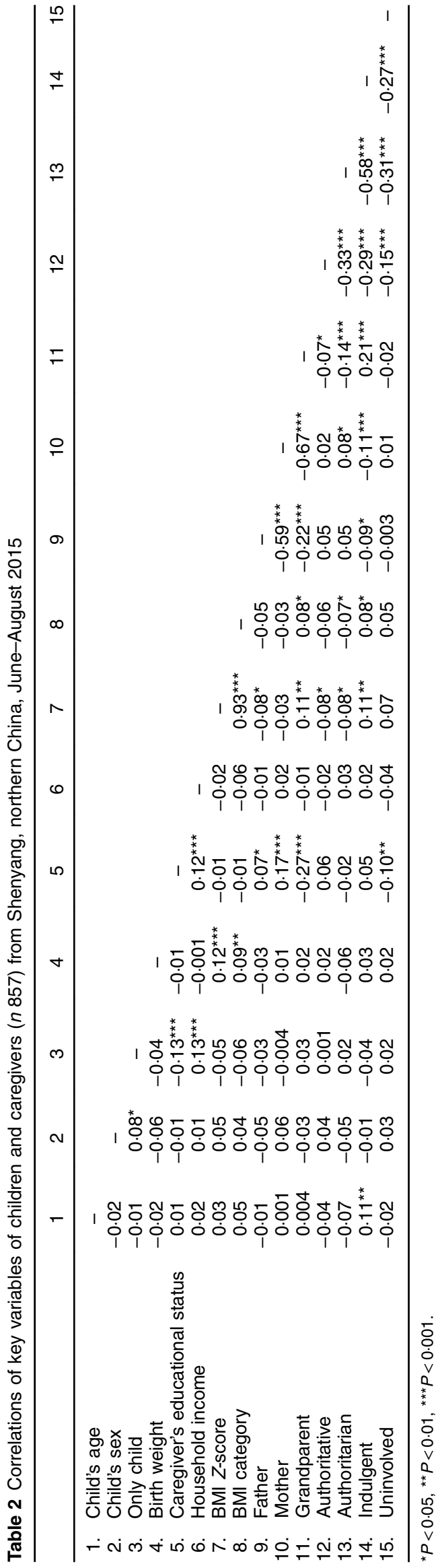

feeding style and BMI $Z$-score. Moreover, according to linear regression analysis, grandparents who reported as main caregiver were independently associated with an increased risk for overweight and obesity in children. This is in agreement with previous research ${ }^{(20)}$. Research on grandparents supports the notion that grandparents' indulgent feeding was considered a key determinant delaying healthy eating habits in the family context ${ }^{(44)}$. In addition, other studies showed parents and grandparents had disagreements about concepts of feeding ${ }^{(30)}$. This may be due to intergenerational differences, such as grandparents' earlier experiences of lack and cultural beliefs that childhood overweight or obesity is a symbol of health, especially in Chinese ${ }^{(45)}$. A recent qualitative study showed that grandparents in Chinese three-generation families were more likely to use indulgent feeding style than parents, which leads to negative health outcomes, especially since grandparents prefer to utilize food as an emotive tool to reflect love and care ${ }^{(44)}$. This is consistent with the study by Farrow which suggested that grandmothers were more likely than mothers to use maladaptive indulgent feeding, for example to elevate their grandchildren's mood $^{(21)}$. What may appear to grandparents as positive reinforcement with food rewards may in fact discourage a child's sense of energy balance, fail to set a good example for the child and disturb the regulation of hunger in the child ${ }^{(46)}$. A possible reason to explain grandparents' preference for the feeding style may be that grandparents do not wish to undermine parental authority in the home and instead use food rewards to gain affection from the child ${ }^{(47)}$.

\section{General comments}

To the authors' knowledge, currently no region or country has reported an effective intervention for underweight or obesity in children ${ }^{(1)}$. Furthermore, compared with that of teenagers and adults, control of weight problems for pre-school children lacks scientific attention ${ }^{(8)}$. Family environment and caregiver types have an impact on the child weight problem epidemic ${ }^{(48)}$. However, studies comparing maternal and paternal or grandparental child feeding are scarce.

Caregivers are the role models in a child's development environment, so their lifestyles and cultures would infiltrate to their offspring, especially to children in the impressionable pre-school age ${ }^{(8)}$. Therefore, studying caregiver-related factors would be beneficial to explore family-based preventions for both obesity and malnutrition. With this information, at-risk populations could be identified at an early age and effective strategies be developed to intervene in the issues of obesity or underweight. Based on our findings, strategies concentrating on promoting child eating practices and well-being should consider the often-ignored contribution of fathers and grandparents. Future research should focus on the clinical aspect of children who are under- or overnourished. 
Table 3 Linear regression models for BMI Z-scores of children ( $n$ 857) from Shenyang, northern China, June-August 2015

\begin{tabular}{|c|c|c|c|c|}
\hline & \multicolumn{2}{|c|}{ Unadjusted model } & \multicolumn{2}{|c|}{ Adjusted model } \\
\hline & $\beta$ & $95 \% \mathrm{Cl}$ & $\beta$ & $95 \% \mathrm{Cl}$ \\
\hline \multicolumn{5}{|l|}{ Feeding style } \\
\hline Authoritative & \multicolumn{2}{|c|}{ Reference } & \multicolumn{2}{|c|}{ Reference } \\
\hline Authoritarian†, $\ddagger$ & -0.37 & $-0.60,-0.15$ & -0.30 & $-0.55,-0.06$ \\
\hline Indulgent† & 0.26 & $0.03,0.49$ & 0.14 & $-0.11,0.39$ \\
\hline Uninvolved & 0.26 & $-0.06,0.58$ & 0.35 & $-0.01,0.70$ \\
\hline Caregiver type & & & & \\
\hline Mother & \multicolumn{2}{|c|}{ Reference } & \multicolumn{2}{|c|}{ Reference } \\
\hline Father†, $\ddagger$ & -0.63 & $-0.98,-0.28$ & -0.66 & $-1.06,-0.27$ \\
\hline Grandparent†,‡ & 0.63 & $0.24,1.01$ & 0.66 & $0.27,1.06$ \\
\hline
\end{tabular}

Models adjusted for child's sex, age, only child and birth weight, and caregiver's education and income.

†Significant result, $P<0.05$ (unadjusted model).

†Significant result, $P<0.05$ (adjusted model).

Table 4 Moderation effect models of feeding style and caregiver type on child BMI Z-score after controlling for confounders $†$ among children ( $n$ 857) from Shenyang, northern China, June-August 2015

\begin{tabular}{|c|c|c|c|c|c|c|c|c|c|}
\hline \multirow[b]{3}{*}{ Feeding style } & \multicolumn{9}{|c|}{ Caregiver type } \\
\hline & \multicolumn{3}{|c|}{ Mothers } & \multicolumn{3}{|c|}{ Fathers } & \multicolumn{3}{|c|}{ Grandparents } \\
\hline & Term & $\beta$ & $95 \% \mathrm{Cl}$ & Term & $\beta$ & $95 \% \mathrm{Cl}$ & Term & $\beta$ & $95 \% \mathrm{Cl}$ \\
\hline \multirow[t]{4}{*}{ Authoritative } & Intercept & $-1 \cdot 30$ & - & Intercept & $-1 \cdot 18$ & - & Intercept & -1.52 & - \\
\hline & ME Authoritative ${ }^{\star *}$ & -0.42 & $-0.75,-0.09$ & ME Authoritative ${ }^{\star *}$ & -0.44 & $-0.77,-0.11$ & ME Authoritative ${ }^{\star *}$ & -0.43 & $-0.76,-0.09$ \\
\hline & ME Mother & -0.11 & $-0.35,0.14$ & ME Father* & -0.32 & $-0.62,-0.01$ & ME Grandparent** & 0.44 & $0.13,0.75$ \\
\hline & Interaction & $-0 \cdot 16$ & $-0.86,0.53$ & Interaction & 0.72 & $-0.09,1.53$ & Interaction & -0.40 & $-1 \cdot 38,0.59$ \\
\hline \multirow[t]{4}{*}{ Authoritarian } & Intercept & 0.55 & - & Intercept & -1.06 & - & Intercept & -1.41 & - \\
\hline & ME Authoritarian** & -0.57 & $-0.54,-0.02$ & ME Authoritarian & -0.16 & $-0.39,0.07$ & ME Authoritarian & -0.10 & $-0.34,0.13$ \\
\hline & ME Mother & -0.26 & $-0.94,-0.21$ & ME Father & -0.29 & $-0.60,0.02$ & ME Grandparent ${ }^{\star \star}$ & 0.48 & $0.15,0.81$ \\
\hline & Interaction* & 0.50 & $0.04,0.95$ & Interaction & -0.51 & $-1 \cdot 13,0 \cdot 10$ & Interaction & 0.13 & $-0.52,0.79$ \\
\hline \multirow[t]{4}{*}{ Indulgent } & Intercept & -0.08 & - & Intercept & -1.08 & - & Intercept & -0.17 & - \\
\hline & ME Indulgent** & 0.67 & $0.31,1.02$ & ME Indulgent & 0.20 & $-0.05,0.44$ & ME Indulgent & 0.12 & $-0.14,0.38$ \\
\hline & ME Mother & 0.16 & $-0.12,0.43$ & ME Father & -0.29 & $-0.61,0.02$ & ME Grandparent & $0 \cdot 11$ & $-0.26,0.47$ \\
\hline & Interaction** & -0.60 & $-1.06,-0.14$ & Interaction & -0.01 & $-0.71,0.69$ & Interaction* ${ }^{\star}$ & 0.54 & $0.01,1.08$ \\
\hline \multirow[t]{4}{*}{ Uninvolved } & Intercept & $-1 \cdot 21$ & - & Intercept & -1.15 & - & Intercept & -1.43 & - \\
\hline & ME Uninvolved* & 0.41 & $0.07,0.76$ & ME Uninvolved* & 0.41 & $0.07,0.76$ & ME Uninvolved ${ }^{\star *}$ & 0.43 & $0.08,0.77$ \\
\hline & ME Mother & -0.11 & $-0.37,0.13$ & ME Father* & -0.32 & $-0.62,-0.01$ & ME Grandparent ${ }^{\star * *}$ & 0.50 & $0.19,0.80$ \\
\hline & Interaction & 0.26 & $-0.46,0.98$ & Interaction & 0.45 & $-0.47,1.38$ & Interaction & -0.80 & $-1.66,0.07$ \\
\hline
\end{tabular}

$\mathrm{ME}$, main effect.

${ }^{\star} P<0.05,{ }^{\star \star} P<0.01,{ }^{\star \star \star} P<0.001$.

†Adjusted for child's sex, age, only child and birth weight, and caregiver's education and income.

It is essential to consider limitations of the present study, which have an influence on avenues for more research. First, our research is limited in being selfreported in nature. The height and weight of the child and food intake data were self-reported by each caregiver but following careful instructions ${ }^{(49)}$. Additional exploratory analyses to objectify measured biometrics and other feeding items should be conducted to promote uniformity. Second, our research is limited in its sampling area. The participants in our sample are only from Shenyang, China. As a next step, a large-scale and representative longitudinal study would be ideal. Third, our research is limited in its cross-sectional nature. The present data were collected at one time point only, which cannot identify a cause-and-effect relationship. Furthermore, our research is limited in its results of correlations. Many of the significant correlations were accounting for less than $1 \%$ of the variance.
Despite these limitations, the present research boasted a relatively large sample size and was representative of China, deepening the understanding of the role of caregivers and their feeding styles in child weight problems and creating the necessary foundation to support the development of family-based obesity interventions. Ultimately, longitudinal investigations are needed to evaluate the long-term effects of these factors and their interactions on child weight status.

\section{Acknowledgements}

Acknowledgements: The authors extend special thanks to all those who participated in the study. Financial support: This research was supported by funds from Shenyang Science and Technology Plan Projects (F14-231-1-57) and Liaoning Distinguished Professor (Liao taught (2013) No. 204). 
The funders had no role in the design, analysis or writing of this article. Conflict of interest: The authors declare no conflict of interest in the submission of this manuscript. Authorship: Formulating the research question(s): X.W. Designing the study: X.W., Y.M. Carrying it out: X.W., J.H., W.L., Z.Z. Analysing the data and writing the article: X.W. All authors approved the manuscript for publication. Ethics of buman subject participation: This study was conducted according to the guidelines laid down in the Declaration of Helsinki and all procedures involving human subjects were approved by the China Medical University. Written informed consent was obtained from all participates.

\section{References}

1. Ng M, Fleming T, Robinson M et al. (2014) Global, regional, and national prevalence of overweight and obesity in children and adults during 1980-2013: a systematic analysis for the Global Burden of Disease Study 2013. Lancet 384, 766-781.

2. Black RE, Allen LH, Bhutta ZA et al. (2008) Maternal and child undernutrition: global and regional exposures and health consequences. Lancet 371, 243-260.

3. Mukabutera A, Thomson DR, Hedt-Gauthier BL et al. (2016) Risk factors associated with underweight status in children under five: an analysis of the 2010 Rwanda Demographic Health Survey (RDHS). BMC Nutr 2, 40.

4. Lloyd LJ, Langley-Evans SC \& McMullen S (2012) Childhood obesity and risk of the adult metabolic syndrome: a systematic review. Int J Obes (Lond) 36, 1-11.

5. Suastika K, Dwipayana P, Saraswati MR et al. (2010) Underweight is an important risk factor for coronary heart disease in the population of Ceningan Island, Bali. Diab Vasc Dis Res 9, 75-77.

6. Reinehr T, Kleber M, Lass $\mathrm{N}$ et al. (2010) Body mass index patterns over $5 \mathrm{y}$ in obese children motivated to participate in a 1-y lifestyle intervention: age as a predictor of long-term success. Am J Clin Nutr 91, 1165-1171.

7. Danielsson P, Svensson V, Kowalski J et al. (2012) Importance of age for 3-year continuous behavioral obesity treatment success and dropout rate. Obes Facts 5, 34-44.

8. Zong XN, Li H \& Zhang YQ (2015) Family-related risk factors of obesity among preschool children: results from a series of national epidemiological surveys in China. BMC Public Health 15, 927.

9. Farrow C \& Blissett J (2012) Stability and continuity of parentally reported child eating behaviours and feeding practices from 2 to 5 years of age. Appetite 58, 151-156.

10. Blissett J (2011) Relationships between parenting style, feeding style and feeding practices and fruit and vegetable consumption in early childhood. Appetite 57, 826-831.

11. Hughes SO, Power TG, Orlet Fisher J et al. (2005) Revisiting a neglected construct: parenting styles in a child-feeding context. Appetite 44, 83-92.

12. Hughes SO, Shewchuk RM, Baskin ML et al. (2008) Indulgent feeding style and children's weight status in preschool. J Dev Behav Pediatr 29, 403-410.

13. Tovar A, Hennessy E, Pirie A et al. (2012) Feeding styles and child weight status among recent immigrant motherchild dyads. Int J Behav Nutr Phys Act 9, 62.

14. Hennessy E, Hughes SO, Goldberg JP et al. (2010) Parent behavior and child weight status among a diverse group of underserved rural families. Appetite 54, 369-377.

15. Vollmer RL \& Mobley AR (2015) Parenting styles, feeding styles, and their influence on child obesogenic behaviors and body weight. A review. Appetite 71, 232-241.
16. Hoerr SL, Hughes SO, Fisher JO et al. (2009) Associations among parental feeding styles and children's food intake in families with limited incomes. Int J Behav Nutr Phys Act 6, 55 .

17. Pai HL \& Contento I (2014) Parental perceptions, feeding practices, feeding styles, and level of acculturation of Chinese Americans in relation to their school-age child's weight status. Appetite 80, 174-182.

18. Rodenburg G, Kremers SP, Oenema A et al. (2012) Associations of children's appetitive traits with weight and dietary behaviours in the context of general parenting. PLoS One 7, e50642.

19. Shloim N, Edelson LR, Martin N et al. (2015) Parenting styles, feeding styles, feeding practices, and weight status in 4-12 year-old children: a systematic review of the literature. Front Psychol 6, 1849.

20. Mena NZ, Gorman K, Dickin K et al. (2015) Contextual and cultural influences on parental feeding practices and involvement in child care centers among Hispanic parents. Child Obes 11, 347-354.

21. Farrow C (2014) A comparison between the feeding practices of parents and grandparents. Eat Behav 15, 339-342.

22. Mallan KM, Nothard M, Thorpe K et al. (2014) The role of fathers in child feeding: perceived responsibility and predictors of participation. Child Care Health Dev 40, 715-722.

23. Khandpur N, Blaine RE, Fisher JO et al. (2014) Fathers' child feeding practices: a review of the evidence. Appetite $\mathbf{7 8}$, 110-121.

24. Vollmer RL, Adamsons K, Foster JS et al. (2014) Association of fathers' feeding practices and feeding style on preschool age children's diet quality, eating behavior and body mass index. Appetite 89, 274-281.

25. Lee HS, Duffey KJ, Kim CI et al. (2013) The relationship between family and child weight status by household structure in South Korea: 2007-2010. Nutr Diabetes 3, e73.

26. Ban L, Guo S, Scherpbier RW et al. (2017) Child feeding and stunting prevalence in left-behind children: a descriptive analysis of data from a central and western Chinese population. Int J Public Health 62, 143-151.

27. Lloyd AB, Lubans DR, Plotnikoff RC et al. (2014) Maternal and paternal parenting practices and their influence on children's adiposity, screen-time, diet and physical activity. Appetite 79, 149-157.

28. Barlow SE \& Expert Committee (2007) Expert committee recommendations regarding the prevention, assessment, and treatment of child and adolescent overweight and obesity: summary report. Pediatrics 120, Suppl. 4, S164-S192.

29. Xiao S (2016) Intimate power: the intergenerational cooperation and conflicts in childrearing among urban families in contemporary China. J Chin Sociol 3, 1-24.

30. Eli K, Howell K, Fisher PA et al. (2016) A question of balance: explaining differences between parental and grandparental perspectives on preschoolers' feeding and physical activity. Soc Sci Med 154, 28-35.

31. Pulgaron ER, Patino-Fernandez AM, Sanchez J et al. (2016) Hispanic children and the obesity epidemic: exploring the role of abuelas. Fam Syst Health 31, 274-279.

32. Sata M, Yamagishi K, Sairenchi T et al. (2016) Impact of caregiver type for 3-year-old children on subsequent between-meal eating habits and being overweight from childhood to adulthood: a 20-year follow-up of the Ibaraki Children's Cohort (IBACHIL) study. J Epidemiol 25, 600-607.

33. Zeng Y \& Hesketh T (2016) The effects of China's universal two-child policy. Lancet 388, 1930-1938.

34. Pearce A, Li L, Abbas J et al. (2010) Is childcare associated with the risk of overweight and obesity in the early years? Findings from the UK Millennium Cohort Study. Int J Obes (Lond) 34, 1160-1168. 
35. Maher EJ, Li G, Carter L et al. (2008) Preschool child care participation and obesity at the start of kindergarten. Pediatrics 122, 322-330.

36. Statistical Bureau of Liaoning Province, Public Security Department of Liaoning Province \& Family Planning Committee of Liaoning Province (2015) Liaoning Economic Statistical Yearbook - 2015. https://www.shujuku.org/ category/liaoning-statistical-yearbook/ (accessed July 2017).

37. WHO Multicentre Growth Reference Study Group (2007) WHO Child Growth Standards: Length/height-for-age, weight-for-age, weight-for-length, weight-for-height and body mass index-for-age: Methods and development. http:// www.who.int/childgrowth/standards/technical_report/en/ (accessed July 2017).

38. Cole TJ, Flegal KM, Nicholls D et al. (2007) Body mass index cut offs to define thinness in children and adolescents: international survey. BMJ 335, 194.

39. Cole TJ, Bellizzi MC, Flegal KM et al. (2000) Establishing a standard definition for child overweight and obesity worldwide: international survey. BMJ 320, 1240-1243.

40. Xiejian (2007) Development and evaluation of psychometric tests of the Chinese version of Caregiver's Feeding Styles Questionnaire. MD Thesis, Chinese Center for Disease Control and Prevention.

41. Hayes AF (2013) Introduction to Mediation, Moderation, and Conditional Process Analysis: A Regression-Based Approach. New York: Guilford Press.
42. Aiken LS \& West SG (1991) Multiple Regression: Testing and Interpreting Interactions. Newbury Park, CA: SAGE Publications, Inc.

43. Joan K, Orrell-Valentea LGH, Whitney A et al. (2007) 'Just three more bites': an observational analysis of parents' socialization of children's eating at mealtime. Appetite $\mathbf{4 8}$, $37-45$.

44. Jiang J, Rosenqvist U, Wang $\mathrm{H}$ et al. (2007) Influence of grandparents on eating behaviors of young children in Chinese three-generation families. Appetite 48, 377-383.

45. Lee A \& Brann L (2015) Influence of cultural beliefs on infant feeding, postpartum and childcare practices among Chinese-American mothers in New York city. J Community Health 40, 476-483.

46. Blissett J, Haycraft E \& Farrow C (2010) Inducing preschool children's emotional eating: relations with parental feeding practices. Am J Clin Nutr 92, 359-365.

47. Knight A (2016) The temporality of food practices: intergenerational relations, childhood memories and mothers' food practices in working families with young children. Fam Relationsh Soc 3, 303-318.

48. Lawman HG \& Wilson DK (2012) A review of family and environmental correlates of health behaviors in highrisk youth. Obesity (Silver Spring) 20, 1142-1157.

49. Goodman E, Hinden BR \& Khandelwal S (2000) Accuracy of teen and parental reports of obesity and body mass index. Pediatrics 106, 52-58. 